\title{
تاريخ انتشار الإسلام في منطقة بنجكولو جزيرة سومطرة، إندونيسيا
}

\author{
Yenni Patriani \\ Institut Agama Islam Negeri (IAIN) Bengkulu \\ yenni.patriani@iainbengkulu.ac.id
}

\begin{abstract}
This paper is about the history of the spread of Islam in Bengkulu region, Indonesia. Sumatra is the sixth islands of the world and the third islands of Indonesia in size after Borneo and Papua. Bengkulu is located in the south of Sumatra. The Arab civilization and cultural relics in Indonesia were numerous, especially in the Bengkulu region of Sumatra. These effects were in fact derived from the power of the Islamic religion. One of the objectives of this research is to highlight the efforts of Arab and Indonesian scholars in spreading Islam in the Bengkulu region, and to clarify the history of Bengkulu before the introduction of Islam, which began with the entry of the monastic buddies during the era of King Ajay Brinah Sikalawi Libung. These are the following questions: How was the life of the people of Bengkulu before the introduction of Islam? What are the Arab cultural and cultural monuments in Bengkulu? To answer these questions, we relied on the descriptive approach.
\end{abstract}

Keywords: Islam, Culture, History, Sumatra, Bengkulu

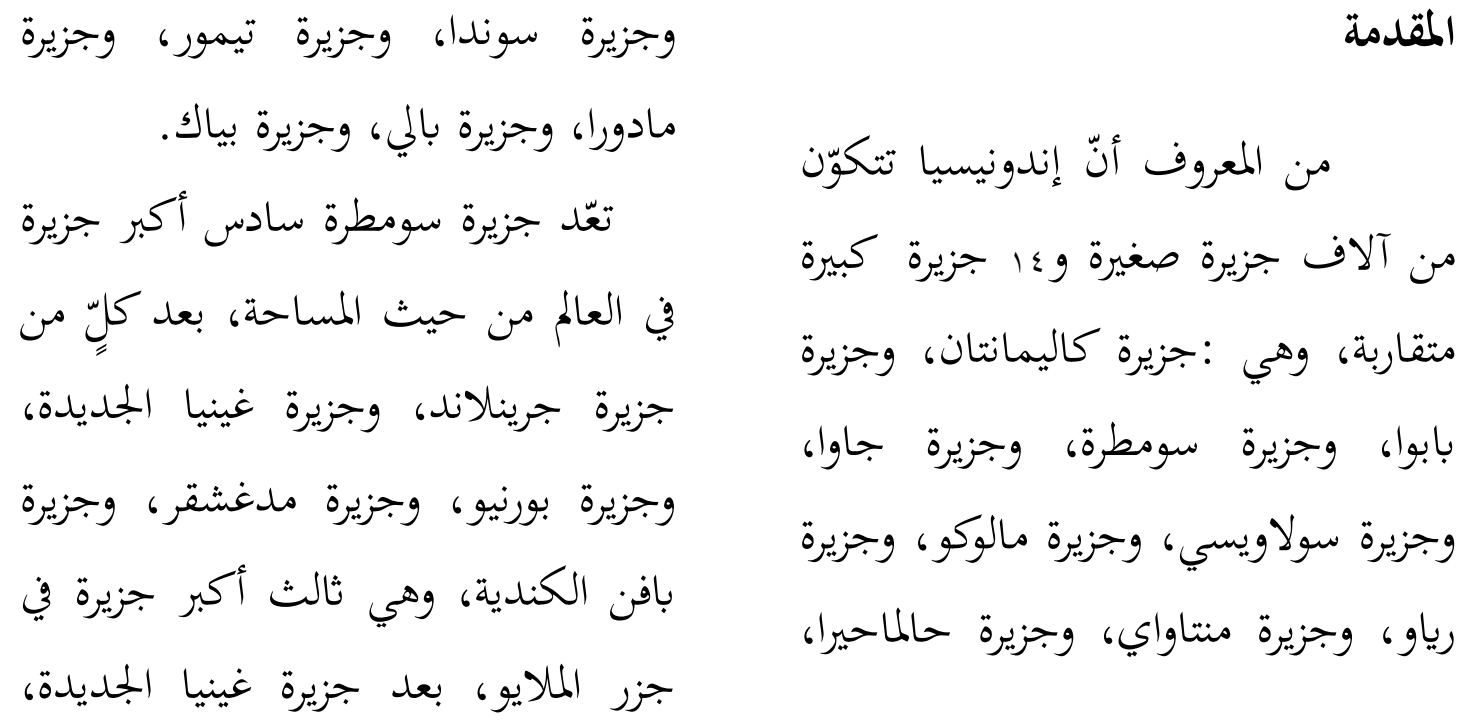


كما أنها إحدى أكثر المناطق السياحية التي تجذب السياح من كل أنحاء العالم. أهم المدن والمعالم والسياحية في سومطرة تنقسم سومطرة إلى عدة أقسام، وهي:

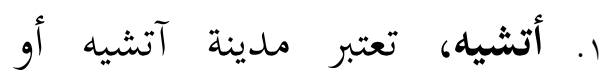
منطقة يدخل إليها الإسلام في إندونيسيا، ولذلك فهي إحدى أهم المدن في سومطرة ـ أهم معالم مدينة آتشيهمتحف التسوناميهو عبارة عن متحف ت تذكاري لضحايا كارثة تسونامي التي أودت بجياة الكثيرين من أبناء مدينة آتشيه الاندونيسية. تمع المين

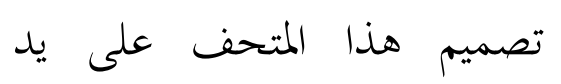
المهندس المعماري الاندونيسي رضوان كامل. وهو يضم العديد من الرسومات والصور التي تُمثل حادثة التسونامي، بالإضافة الم لي السقف المغظطى بأسماء ضحايا هذه الكارثة الطبيعية. كما يعتبر هذا المتحف من أكثر الأماكن إستقطابًا للزوار في آتشيه.
وجزيرة بورنيو؛ حيث تبلغ مساحة جزيرة

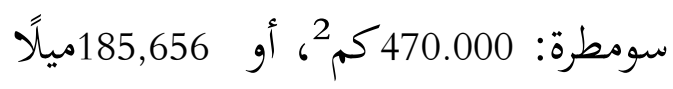
مربعًا، والمساحة التي تحتلّها جزيرة سومطرة قريبة من مساحة ولاية كاليفورنيا الأمريكيّة، وهي قريبة أيضًا من مساحة العراق، والمغرب، وتايلاند. وتعتبر جزيرة

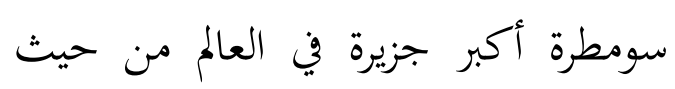
عدد السكّان؛ حيث يبلغ عدد سكّاها

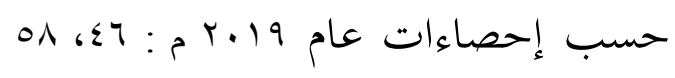
مليون، يتكون من \&هو جr مليون ذكورا و و

جزيرة سومطرة هي واحدة من أجمل الجزر في آسيا والعالم، فهي ذات طبيعة جبلية مليئة بالوديان والغابات التي تجعل منها معلمًا طبيعيًا غاية في الروعة. تعتبر جزيرة سومطرة ثالث أكبر الجزر في إندونيسيا وسادس أكبر جزيرة في العالم. وهي تمتاز بتنوع الحياة الطبيعية فيها، فهي موطن للعديد من الحيوانات والنباتات النادرة التي قد لا تجدوفها في مكان آخر.

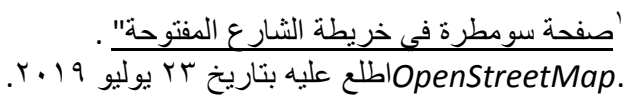


الأمر الذي يبعل منه تحفة فنية بكُل معنى الكلمة.

r. رياو، واحدة من أغنى المقاطعات

في إندونيسيا، فهي غنية بالموارد

الطبيعية ومنبع غر سياك. تتموي

رياو على العديد من المباني

التقليدية ذات

الاندونيسي التُراثي، بالإضافة إلى

الغابات والتلال الساحرة، كما أها الإنا

من أشهر المناطق السياحية في

إندونسيا لما تحتويه من معالم رائعة

الجمال. أهم معالم رياو السياحية

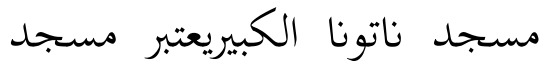

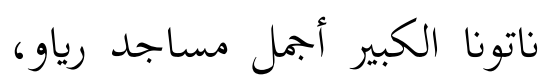

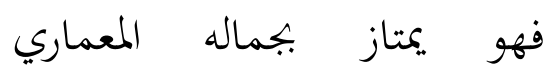

وتصميمه الإسلامي الرائع، حيث

زُخرف بالكثير من الآيات القرآنية

بالإضافة إلى قُبته التي تشبه قبة الايات الترانية

$$
\text { تاج معل في الهند. }
$$

ء. بنجكا بيليتونج، هي جزيرة تقع

شرق سومطرة، وتعتبر إداريا جزء

من سومطرة، إندونيسيا، وييلغ
ז. ميدان، تقع في سومطرة الشمالية

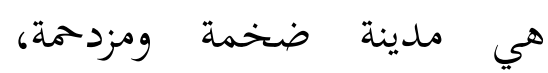

تشتهر بفسيفسائها البشري الكبير

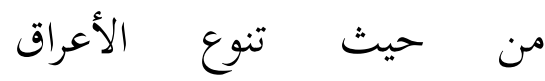

والأجناس، وتقع في شثمال جزيرة

سومطرة، يقطنها المالاويون،

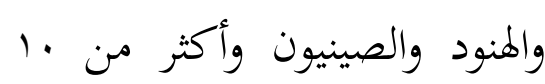

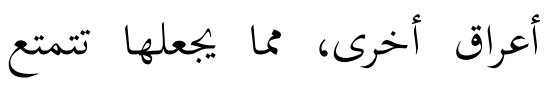

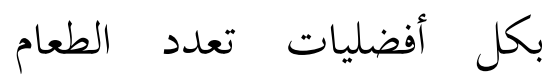

والمطاعم الشهية، ناهيك عن افنيات تعدد الشعام

شهرتا المعروفة بحليب الماعز

الطازج، فهي تشكل مصدر لمعروة

تصدير رئيسي له في إندونيسيا.

ميدان هي مدينة الطعام والتمتع

به وعلى من يزورها أن يأتي إليها

وهو جوعان. أهم معالم مدينة

ميدانقصر ميمونأحد أهم معالم

مدينة ميدان وسومطرة بامتياز،

حيث يتمتع هذا المبنى الرائع

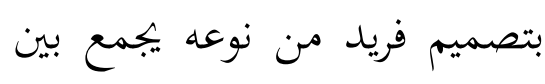

الطراز التراثي الإسلامي،

والمالاوي، والهندي و والإسباني، الإناي، 
الزهرة. تفرد هذه الزهرة هو عدم وجود جذور وأوراق وسيقان. هذا النبات هو طفيلي بسبب عدم وجود الكلوروفيل والهاوستوريا. غالبًا ما تنمو هذه الزهرة وتوجد في تابا بينانجونج الأول وتابا

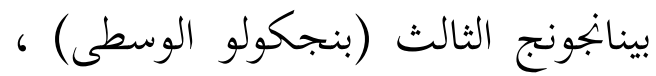
وفي مقاطعة كيباهيانج ، وفي مقاطعة ريجانج ليبونج. لذلك، بنجكولو يطلق عليها لقب أرض رافليسيا. يحدها المحيط الهندي ولديه ساحل طويل وجميل وشواطئ جميلة، أشهرها Pantai Panjang. وفيها أيضا حصن Marlborough تاريخ بنجكولو وتقسيمها

بنجكولو هي مقاطعة أندونيسيا ، وتقع في الساحل الجنوبي الغربي

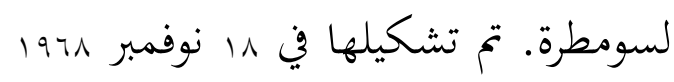
عن طريق فصل منطقة إقامة بنجكولو السابقة عن مقاطعة سومطرة الجنوبية بموجب القانون رقم ه لعام 197 إنم الانتهاء منه بموجب اللائحة الحكومية رقم

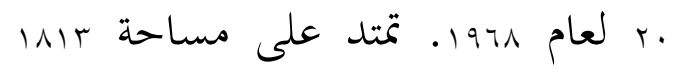

عدد سكاها حوالي مليون نسمة. تشتهر جزيرة بانجكا بشواطئها الجميلة. بشكل عام ، ت تتمتع الشواطئ ي بانجكا بالرمال البيضاء الناعمة ولكن بعضئ لبنها أصفر ذهبي مثل حبات الأرز. الشاطئ ينحدر مع موجة كبيرة إلى حد ما وتحيط به الصخور البركانية الفريدة والجميلة. ه. بنجكولو، واحدة من المحافظات الواقعه في منطقه سومطرة تحت رعاية الحاكم روحيدين ميرشاه Rohidin) (Mersyah) المصدر الأصلي لزهرة رافليسيا أرنولدي. خلال الحكم البريطاني، كانت هذه الزهرة شائعة العلم من قبل السيد توماس رافليس والدكتور أرنولد في عام هاري منطقة الغابات الواقعة بين مقاطعتي كيباهيانج وبنجكولو الوسطى. هذه الزهرة هي أكبر زهرة في العالم، ويبلغ قطرها ... سم. تتطلب هذه الزهرة من 7

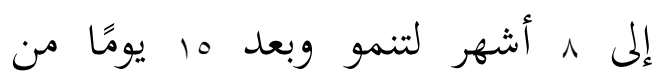


تشمل بنجكولو أيضًا جزيرة

ميجا وجزيرة إنغانو في المحيط الهندي.

تمتلك بنجكولو هبه كيلومتراً من الساحل

على طول المحيط الهندي على جانبها

الغربي ، من دوسون بارو بيلوكان في موكو

موكو ريجنسي إلى تيبينج أنسال في كور

ريجنسي. بنجكولو هي موطن لكثير من

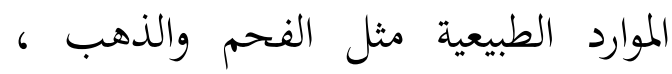

ولديها موارد طاقة حرارية كبيرة ومحتملة.

ومع ذلك ، فهي أقل تطوراً من المحافظات

$$
\text { الأخرى في سومطرة'. }
$$

تنقسم هذه المنطقلة إلى 9 مديرية عمودية

و ملدينة رئيسية :

\begin{tabular}{|c|c|c|}
\hline رئيس & عاصمة & مدينة رئيسية اسيرية أو \\
\hline حلمي حسن & بنجكولو & $\begin{array}{r}\text { مدينة } \\
\text { (Bengkulu } \\
\text { Kota) }\end{array}$ \\
\hline غسنان & $\begin{array}{r}\text { مانا } \\
\text { (Manna) }\end{array}$ & مديرية \\
\hline
\end{tabular}

كفحة بنغكولو في"GeoNames ID. GeoNames ID.

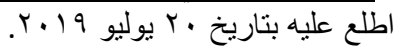

كم ب ، ويحدها مقاطعات سومطرة الغربية من الشمال ، جامبي من الشمال الشرقي ، لامبونج من الجنوب الشرقي ، جنوب سومطرة من الشرق ، والمحيط الهندي من الشمال الغربي والجنوب والجنوب الغربي

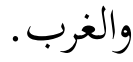

بنجكولو هي أكبر 0ب مقاطعة

حسب المنطقة ؛ وهي مقسمة إلى تسع مقاطعات ومدينة بنجكولو ، العاصمة وأكبر مدينة. بنجكولو هي أيضًا المقاطعة

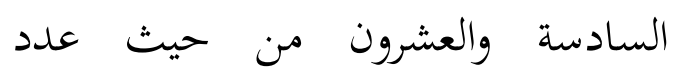
السكان في إندونيسيا. وفقا لبيان صادر عن Badan Pusat Statistik ، فقد حقق أعلى مؤشر للتنمية البشرية الحادي عشر بين المقاطعات ، حيث سجل حوالي

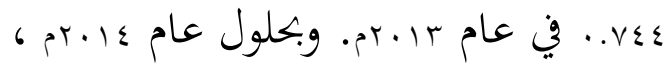
تحتل المقاطعة المرتبة یی في أعلى الناتج المحلي الإجمالي و ·r في أعلى متوسط

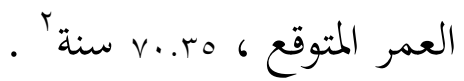

\footnotetext{
${ }^{2}$ Statistik Indonesia 2018". Badan Pusat Statistik. Retrieved July 23, 2018.
} 


\begin{tabular}{|c|c|c|}
\hline & & موكوموكو \\
\hline أحمد & جوروب & 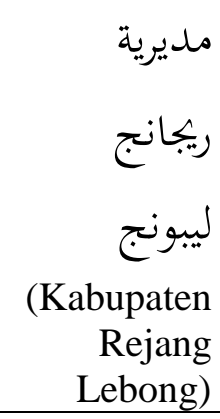 \\
\hline $\begin{array}{r}\text { بوندرا جايا } \\
\text { (Bundra } \\
\text { Jaya) }\end{array}$ & $\begin{array}{c}\text { تايس } \\
\text { (Tais) }\end{array}$ & $\begin{array}{r}\text { مديرية } \\
\text { (Kabupaten } \\
\text { Seluma) }\end{array}$ \\
\hline
\end{tabular}

عادات الججتمع البنجكولوي وتقاليده

العادات والتقاليد مألوفة تماما

مع مجتمع بنجكولو، بما في ذلك: قماش باتيك بيسوريك، وهو قطعة قماث بها حروف عربية غير مشكّلة. و وسكان بنجكولو يرتنفلون بالاحتفالات التقليدية 6 مثل احتفال ختان الولد ، ومراسم الزفاف التقليدية ، ومراسم حلاقة شعر طفل حديث الولادة. وأشهر الاحتفالات "Tabut” التقليدية في بنجكولو هو حفل

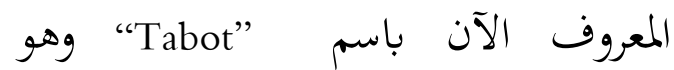
احتفال تقليدي يقام من الأول إلى العاشر

\begin{tabular}{|c|c|c|}
\hline $\begin{array}{c}\text { موليادي } \\
\text { (Gusnan } \\
\text { Mulyadi) }\end{array}$ & & $\begin{array}{r}\text { الجنغولو } \\
\text { (Kabupaten } \\
\text { Bengkulu } \\
\text { Selatan) } \\
\end{array}$ \\
\hline $\begin{array}{r}\text { فيري رملي } \\
\text { (Ferry } \\
\text { Ramli) }\end{array}$ & $\begin{array}{r}\text { كارانج } \\
\text { تينهج } \\
\text { (Karang } \\
\text { Tinggi) }\end{array}$ & $\begin{array}{r}\text { مليرية } \\
\text { الوسطى } \\
\text { (Kabupaten } \\
\text { Bengkulu } \\
\text { Tengah) }\end{array}$ \\
\hline $\begin{array}{r}\text { ميان } \\
\text { (Mian) }\end{array}$ & $\begin{array}{r}\text { أرجا ماكمور } \\
\text { (Arga } \\
\text { Makmur) }\end{array}$ & $\begin{array}{r}\text { مديرية } \\
\text { الشمالية } \\
\text { (Kabupaten } \\
\text { Bengkulu } \\
\text { Utara) }\end{array}$ \\
\hline $\begin{array}{r}\text { غسريل فوزي } \\
\text { (Gusril } \\
\text { Fauzi) }\end{array}$ & بينتوهان & $\begin{array}{r}\text { مديرية كاور } \\
\text { (Kabupaten } \\
\text { Kaur) }\end{array}$ \\
\hline هداية الله & كيباهيانج & 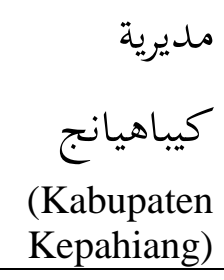 \\
\hline 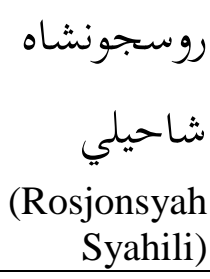 & $\begin{array}{r}\text { موارا أمان } \\
\text { (Muara } \\
\text { Aman) }\end{array}$ & $\begin{array}{r}\text { مديرية ليبونج } \\
\text { (Kabupaten } \\
\text { Lebong) }\end{array}$ \\
\hline خير المدى & موكوموكو & \\
\hline
\end{tabular}


الوعي بين الزعماء الدينيين لبناء الوئام الاجتماعي والعلاقات الداخلية والدينية التي تكون آمنة وسلمية ومحترمة أمر جيد للغاية. تقريبا لم يسمع أي تعارض بين الدين أو العرق هناك.

Kل Ke bukit ، فيفة حياة المجتمع المحلي samo mendaki, ke lurah samo menurun, yang berek samo dipikul, yang ringan samo dijinjing, Bulek Air Kek " التعاون على العمل ‘Bulek kato kek sepakat" Pembuluh وهو ما يعني أهمية الشورى في حياة الفرد

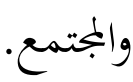

دخول الإسلام في بنجكولو، والعلماء والآثار الإسلامية في بنجكولو

إن تتبع آثار تاريخ الإسالام في

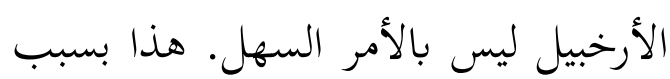
وجود العديد من المصادر الأولية التي لم تعد موجودة. ولكن لا يزال من الممكن إعادة قراءة تاريخ الأرخبيل من خلال بقاياها المتبقية. بما في ذلك تاريخ وصول
من محرم كل عام ، للاحتفال بوفاة حسن وحسين ، حفيد العائلة الشيعية في معركة كربلاء عام ال" هجري. في احتفال

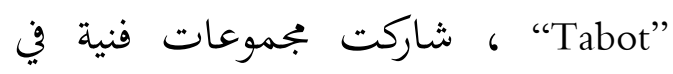
مقاطعة بنجكولو بالعديد من المعارض والمسابقات السمكية وتيليونج تيلونج وغيرها من الفنون ، محا جعلها مكانًا ترفيهيًا شهيرً وأحد التقاويم السياحية السنوية.

هناك أربع لغات إقليمية يستخدمها شعب بنجكولو ، وهي: لغة الملايو، ولغة ريجانج، ولغة بيكال، ولغة ليمباك. ينشأ سكان مقاطعة بنجكولو من ثلاث قبائل كبيرة تتكون من قبيلة ريبانغ وقبيلة ساراواي وقبيلة الملايو. تحتوي بنجكولو على العديد من الأغاني الإقليمية مثل سيلينجيك ، كاراكاك كاراكاك ، ولالان باليك. في بجال الحياة الدينية ، يعد الوعي بالقيام بالطقوس الدينية لأغلبية السكان من بئن المسلمين من الناحية الكمية جيدًا. إن 
بنجكولو ، إلى جبل الأحدب في عام Vاعا م ، ثم بدأ في نشر الإسلام ونشره مع الناس على جبل بنجكوك (نثمال بنجكولو). تم هناك نسخة أخرى ، وهي

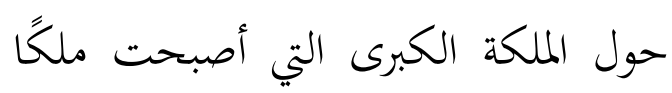
لمملكة غر سيروت ، وهي نسب مملكة بانتن. يقال إن مملكة بانتن مملكة إسلامية. لذلك كانت الملكة أغونغ نفسها مسلمة منذ البداية. نسخة أخرى هي من خلال زواج السلطان مظفر سياح

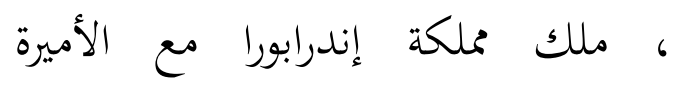

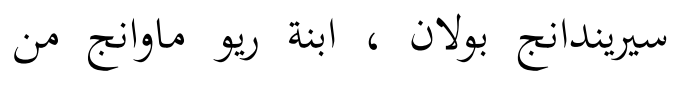
مملكة ليبونج. ثم كانت هناك أسباب عديدة لانتشار الإسلام في بنجكولو كالصداقة والزواج بين بوتري كيمايون من

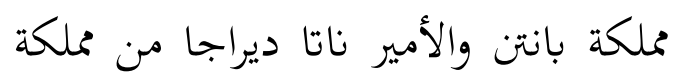
سيليبار. نسخة أخرى هي من خلال العلاقات مع مملكة باليمبانج داروسلام مع الملك ديباتي تيانغ إمبات في ليبونج بعد طرد المتنمرين من شعب بوغيس. ثمان هناك أيضًا نسخة يُقال إن الإسلام فيها
الإسلام إلى الأرخبيل. المحدد هو دخول الإسلام إلى أرض بنجكولو. كما هو الإشيل. الإدد هو دشول معروف أن بنجكولو قبل وأثناء الفترة الاستعمارية ، كانت منطقة تتكون من

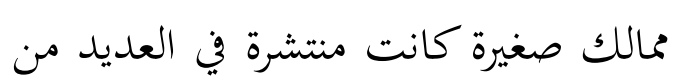
المناطق. مثل مملكة غر سيروت ، ومملكة

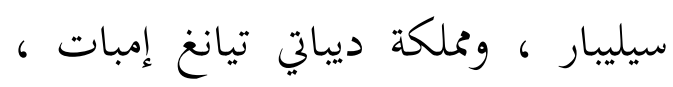

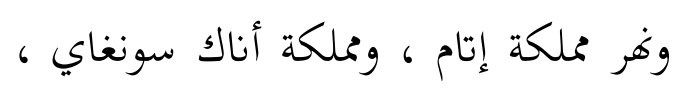
والعديد من الممالك الأخرى. تختلف هذه إنه

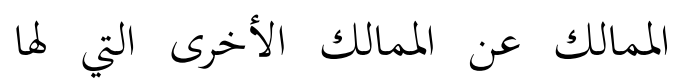
سيطرة مثل البلد وما إلى ذلك. لأن الأن المان

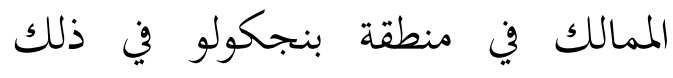
الوقت كانت أكثر من مزيج من القرى الصغيرة المتمتعة بالحكم الذاتي التي يقودها لترنا

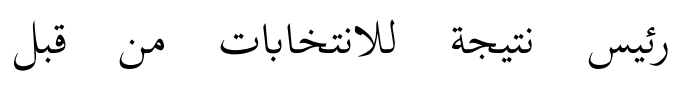

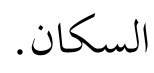

إذن ، كيف دخل الإسلام أرض

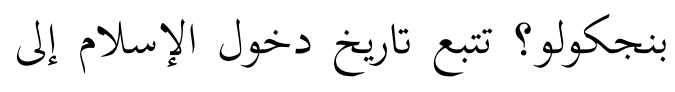
بنجكولو في الواقع لا يزال هناك العديد

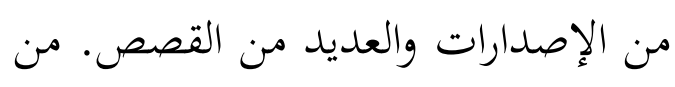
بينها قصة رجل دين من آتشيه يدعى الاصدات واعلديل من العصن Tengku Malin Muhidin 
محله فيما بعد ابنه كي كارانج نيو الذي

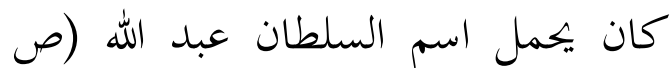

90). يُعتقد أن كي كارانج نيو يقبل الدال الإسلام من صهره ، ملك مملكة إندرابورا

(الساحل الجنوبي لسومطرة الغربية).

بعد ذلك ، كأقدم مجموعة

عرقية ، انتقل شعب Rejang إلى مناطق مختلفة. واحد منهم إلى بنجكولو تينغجي. ثم في بنجكولو تينغجي أسسوا مملكة تسمى غر سيروت ، بقيادة الملكة الكبرى. في رحلته ، عندما كان غر مملكة سيروت بقيادة راجا أناك دالام موارو بانجكاهولو ، كانت هناك معركة كبيرة بين جيش أتش الملكي الذي كان بقيادة السلطان إسكندر مودا ومملكة سونغاي

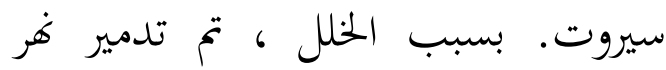
سيروت الصغير في النهاية. ثم هربت بقايا المملكة لجأوا إلى جبل بونجكوك (منطقة شمال بنجكولو) لتقليص الإستراتيجية التالية. ثم كان على جبل الحدب أن نجل التحال

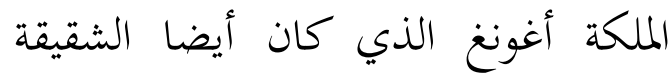

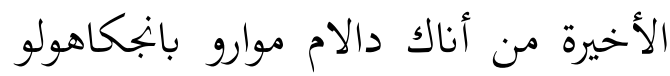

له تأثير عندما أصبحت منطقة موكوموكو لاحقًا مملكة موكوموكو.

تتبع آثار الإسلام في بنجكولو

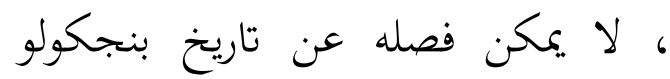
نفسه. حيث في ذلك الوقت، اعتقد أهل بنجكولو بوجود الآلة المختلفة. وكانوا

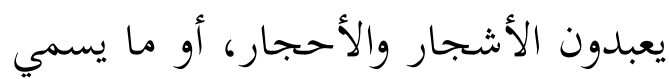
بمصطلح (dynamism)، ويعبدون أرواح الأجداد والقدامى، أو ما يسمى بمصطلح (animism) (aيعتدون أن هذه الأشياء قادرة على حفظ حياة الأحياء. كل هذه المعتقدات لا تزال موجودة حتى اليوم. لنعرف دخول الإسلام في إنان بنجكولو ، لا يمكننا أيضًا أن نخره من الإنام النظام الاجتماعي الحالي. بالإضافة إلى لئل تطوير الممالك والثناقف وكذلك موكب الزواج والتجارة وغيرها. كما هو مذكور في كتاب "دخول الإسلام وتطوره" في مقاطعة بنجكولو Vا.r، تعتبر قبيلة ريجانغ هي أقدم السكان في بنجكولو. وهم يعيشون في رينا سقلاوي. وقد قادت رينا ريو ماوانج هذا رينيه سيكاوي الذي حل 
بين مملكة وRejang Sabah ومملكة بالينبانج دار السلم. ومن خلال هذا انتشر الإسلام في بنجكولو. ثم تطورت مرة

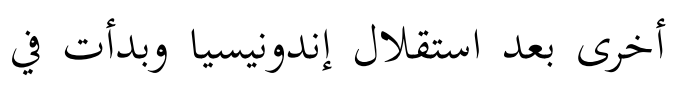
دخول وتطوير منظمات مختلفة مثل اتحاد

التربية والمحمدية وجمعية غضة العلماء. جهود العلماء في نشر الإسلام والآثار الإسلامية في بنجكولو

ومن علماء بنجكولو الذين طارت

شهرتم في أنحاء العالم الإسلامي في

عصرهم من القرن الرابع عشر إلى القرن

العشرين، هم :

1. الإمام مولانا يشاد، وهو رجل

الدين علي زين العابدين بن

الحسين بن علي بن أبي

طالب. جاء إلى Bandar

Sungai Serut

الخميس، بسبام / 1ג جمادى

الأولى Vr هـ. وقيل إنه أول
وهي بوتري غادينغ سيمباكا متزوج من

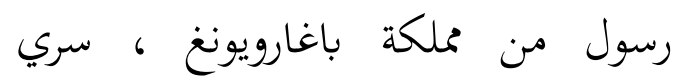
باجيندو ماهاراجو ساكتي. ثم أسسوا مملكة غر Lemau كإصدار آخر من الإسلام في بنجكولو. وهي عبر محلكة Pagaruyung التي كان مبعوثوها مسلمين من قبل وأصبحوا ملوكًا

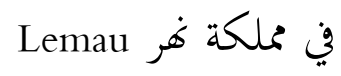

ثم بعد أن أصبح الوضع آمنا

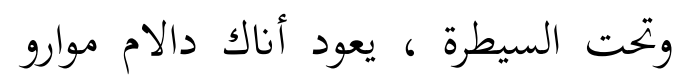

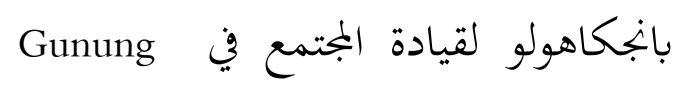
Bungkuk من آتشيه يدعى مالين محي الدين الذي نشر الدعاية في منطقة بولد الحدباء بينانجونج بنجكولو الشمالية. هذا مكتوب

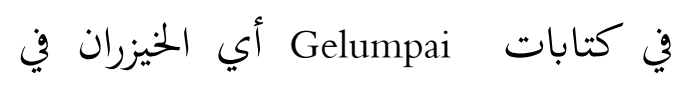

منطقة Komering Ulu ثم دخل الإسلام إلى بنجكولو

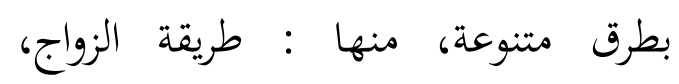
وبطريقة صداقة بين مملكة Selebar ومملكة بانتين، كانت مملكة بانتين إحدى الممالك الإسلامية في الأرخبيل. وبطريقة صداقة بانتين إحلى

114 


$$
\begin{aligned}
& \text { موكوموكو، دفن في منطقة } \\
& \text {.Sungai }{ }^{\circ} \text { Gading } \\
& \text { ء. تينجكو ماليم محي الدين، } \\
& \text { المتوفى سنة Vامو وهو } \\
& \text { الداعي من أتشيه، جاء إلى }
\end{aligned}
$$

Gunung Bungkuk Sungai

. وكان يدعو ملك . Serut.

Ratu Agung

وحده. وأسلم هذا المللك .

ه. الشيخ مُحَّم أمين. هو من

أصول جزيرة نياس سومطرة

الشمالية، لديه سبع زوجات.

وبنى مسجد المنار في منطقة

مانا، بنجكولو الجنوبية. توفي

${ }^{5}$ Ade Oka Hendrata dkk (2013), Peradaban Pantai Barat Sumatra: Perkembangan Hunian dan Budaya di Wilayah Bengkulu, Ombak : Yogyakarta, P. 157-158.

${ }^{6}$ Gadjahnata, Masuk dan Berkembangnya Islam di Sumatra Selatan (1986), UI Press : Jakarta, P. 137.
من قام بكفل تابوت في

بنجكولو ودعا الناس إلى

الإسالام ثم عاد إلى مكة

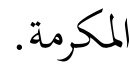

r. Ampar الشيخ عبدالرحمن/

Batu (المتوف سنة بrr|م)؛

كان يدعو مجمتمع بنجكولو

إلى الإسلام مع الإمام مولانا

يشاد. توفي في يوم الخميس

r) أبريل بrr|r

شعبان rrvه ودفن في كرباء

بنجكولو، ومعه كذلك الشيخ

سحاب الدين عبدالله والشيخ

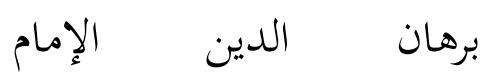

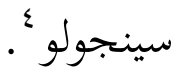

r. الشيخ مُطلاك كان يدعو

الناس إلى الإسالام في منطقة

${ }^{4}$ Syihril, Buku Putih Tabut bencoolen. P. 23 


$$
\begin{aligned}
& \text { ووأصبح قائد حرب خلال } \\
& \text { حرب Diponegoro } \\
& \text { المستعمرين الهولنديين } \\
& \text { جاوا، وقبض عليه المولنديون } \\
& \text { وأخذوه إلى منطقة بنجكولو } \\
& \text { سنة سبرام. في بنجكولو علّم } \\
& \text { المجتمع البنجكولوي إلى دين } \\
& \text { الإسالم. وتوفي في بنجكولو } \\
& \text { سنة 1100/م، ودفن في باجاك } \\
& \text { Bajak, Teluk ) تيلوك سيجارا } \\
& \text { (Segara } \\
& \text { 1 } \\
& \text { ^. الشيخ علي، هو يمني من } \\
& \text { منطقة حضرة الموت. دعا } \\
& \text { الناس إلى الإسلام في منطقة } \\
& \text { كاوور، }
\end{aligned}
$$

${ }^{9}$ Uka Tjandrasasmita (2008), Masjid dan Makam Bersejarah di Sumatra, Departemen Kebudayaan dan Pariwisata : Jakarta, P. 173.

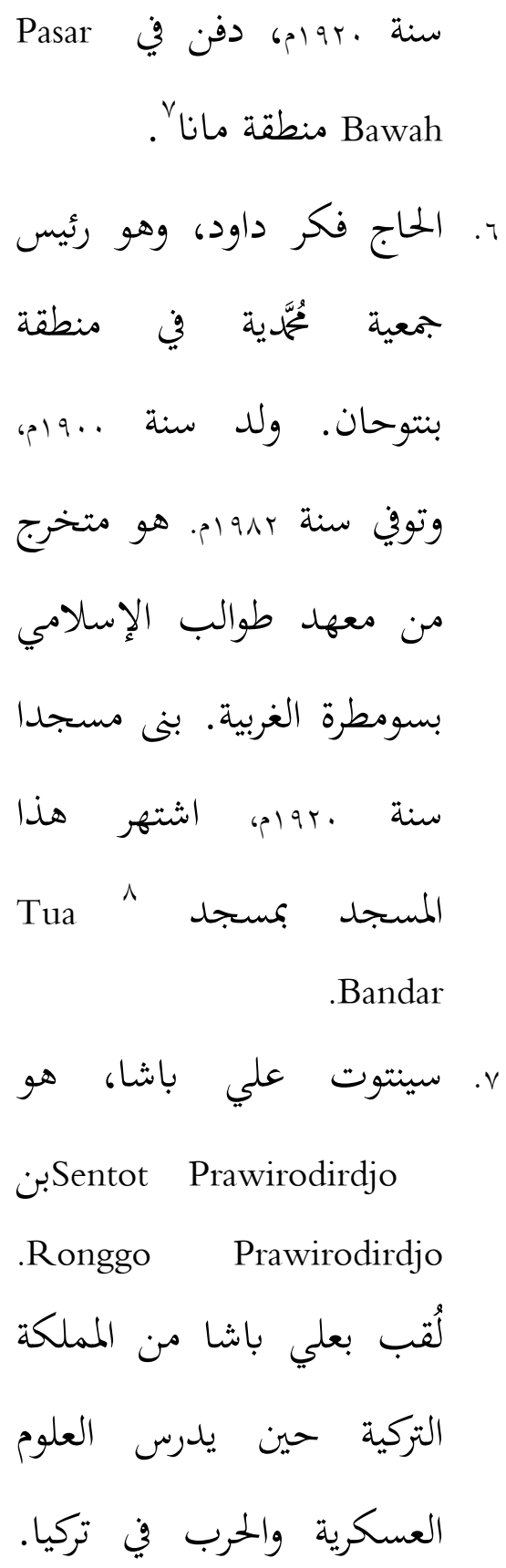

${ }^{7}$ Wizin Juliadi (2016), Perkembangan Is/am Islam di Kec. Pasar Manna Kab. Bengkulu Selatan Abad XX, Skripsi, Prodi SKI IAIN Bengkulu, P. 5.

${ }^{8}$ Ade Oka Hendrata dkk (2013), op.cit, P. 4850 


$$
\begin{aligned}
& \text { بحلس بنجولو الإسلامي } \\
& \text { ورئيس الشؤون الدينية. توفي } \\
& \text { سنة ودفن } \\
& \text { كيركاب } \\
& \text { • ا. الحاج النواوي، كان يدرس في } \\
& \text { مدرسة دار العلوم الدينية } \\
& \text { الإسلامية في مكة المكرمة }
\end{aligned}
$$

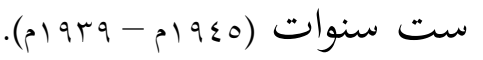

$$
\begin{aligned}
& \text { وبعد سنوات، أنشأ مدرسة } \\
& \text { نور } \\
& \text { الإسالمية، وكان رئيس هذه } \\
& \text { المدرسة من سنة } \\
& \text {. } \\
& \text { سنة ع ا9 ام - أصبح } \\
& \text { رئيس بنتشاسيلا } \\
& \text { الإسلامي بنجكولو 'ا . }
\end{aligned}
$$

\footnotetext{
${ }^{11}$ Hery Noer Aly dkk (2014), Geneologi dan Jaringan Ulama di Kota Bengkulu, Laporan Penelitian, LPPM IAIN Bengkulu, P.35-41.

12 Ibid, P. 76-87.
}

الشاكرين في بنتوحان سنة

$$
\text { . plara-plaro }
$$

9. الحاج عبد المطلب، ولد في

قرية

الشمالية في أب أغسطس

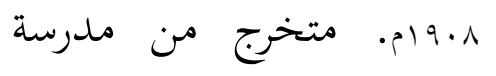

سنة IVorvolg School

وبعد سنة سافر إلى مكة

المكرمة لأداء المج. وفي سنة

Candung إوام إم إلى

Bukit Tinggi

لطلب العلم في مدرسة تربية

الإسالامية تحت رعاية الشيخ

سليمان الرسولي. وبعد التخرج

من هذه أمنأ

مدرسة تربية الإسالامية في

كيركاب. وكان من أعضاء

\footnotetext{
${ }^{10}$ Ferdian Syaputra (2015), Masjid Jami' Asy Syakirin dalam Perkembangan Islam di

Bintuhan, Makalah, Prodi SKI IAIN Bengkulu, P.3.
} 
وتحوّل هذا المعهد إلى جامعة

بنجكولو الإسلامية الحكومية

سنة rا.r إلى اليوم. كان الحاج

بدر المنير يحبّ أن يعين دين

الله فأنشأ معهد روضة العلوم

الإسلامي في سيلوما ورئيس

جمعية هضة العلماء

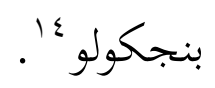

هؤلاء العلماء المسلمون في

بنجكولو الذين نفتخر بجهودهم في نشر

$$
\text { الإسلام في أرض رافليسيا. }
$$

\section{الخاتمة}

سومطرة سادس جزر العالم وثالث

جزر إندونيسيا حجما بعد بورنيو وبابوا.

ومنطقة بنجكولو تقع في جنوب سومطرة،

وأغلب سكاها مسلمون. وبنجكولو

واحدة من المحافظات الواقعه في منطقه

${ }^{14}$ Ibid, P. 126-139
ו. الحاج جمع النور. هو أحد

أعضاء اللجنة في تأسيس كلية

أصول الدين في جوروف،

وكان نائب العميد لهذه

الكلية، وعميد كلية الشريعة

والتربية في بنجكولو. ومدير

معهد الوزارة الدينية سنة

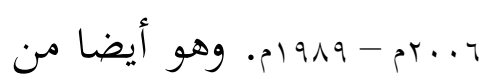

أعضاء جمعية هضة

$$
\text { العلماءs 'اء }
$$

ז.ا. الحاج بدر المنير حميدي، هو

متخرج من مدرسة تربية دينية

إسلامية ل ل ملمدرسين

بباليمبانج، سنة سجوام. وصار

عميد كلية التربية ومدير

المعهد العالي الحكومي للعلوم

الإسلامية سنة r..rم-19971م.

${ }^{13}$ ibid 
دخول وتطوير منظمات مختلفة مثل اتحاد التربية والمحمدية وجمعية غضة العلماء. وفي بنجكولو علماء مسلمون يهتمون بالإسلام، وأنشؤوا المدارس و والمعاهد الإسلامية والمساجد.

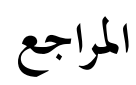

صفحة بنغكولو في_GeoNames ID" r. GeoNames ID.

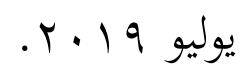

صفحة سومطرة في خريطة الشارع المفتوحة" .

TropenStreetMap.

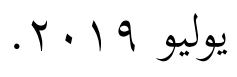

Ade Oka Hendrata dkk (2013), Peradaban Pantai Barat Sumatra : Perkembangan Hunian dan Budaya di Wilayah Bengkulu, Ombak : Yogyakarta.

Ferdian Syaputra (2015), Masjid Jami' Asy Syakirin dalam Perkembangan Islam di Bintuhan, Makalah, Prodi SKI IAIN Bengkulu.
سومطرة الأصلي لزهرة رافليسيا أرنولدي. تنقسم هذه المنطقلة إلى 9 مديرية عمودية و مدينة رئيسية. وإن دخول الإسلام والآثار الإسلامية في بنجكولو لا يمكن فصله عن تاريخ بنجكولو نفسه. وكان أهل بنجكولو - قبل دخول الإسلام، يعتقدون بوجود الآلمة المختلفة. وكانوا يعبدون الأشجار والأحجار، أو ما يسمي بمصطلح (dynamism)، ويعبدون أرواح الأجداد والقدامى، أو ما يسمى بمصطلح (animism)، ويعتقدون أن هذه الأشياء قادرة على حفظ حياة الأحياء. ثم دخل الإسلام إلى بنجكولو بطرق متنوعة، منها : طريقة الزواج، وبطريقة صداقة بين مملكة Selebar بين مملكة Rejang Sabah وملكة بالينبانج دار السلم. ومن خلال هذا انتشر الإسلام في بنجكولو. ثم تطورت مرة أخرى بعد استقلال إندونيسيا وبدأت في 
Kebudayaan dan Pariwisata : Jakarta.

Statistik Indonesia 2018". Badan Pusat Statistik. Retrieved July 23, 2018.

Syihril, Buku Putih Tabut bencoolen

Wizin Juliadi (2016), Perkembangan Islam Islam di Kec. Pasar Manna Kab. Bengkulu Selatan Abad XX, Skripsi, Prodi SKI IAIN Bengkulu.
Gadjahnata, Masuk dan

Berkembangnya Islam di Sumatra Selatan (1986), UI Press : Jakarta.

Hery Noer Aly dkk (2014), Geneologi dan Jaringan Ulama di Kota Bengkulu, Laporan Penelitian, LPPM IAIN Bengkulu.

Uka Tjandrasasmita (2008), Masjid dan Makam Bersejarah di Sumatra,

Departemen 